\title{
Role of Amniotic Fluid Index in Prediction of Fetal Distress During Labor in Uncomplicated Pregnancies at 40 Weeks and Beyond
}

\author{
Semenova $\mathrm{ER}^{1 *}$ and Ruhlyada $\mathrm{NN}^{2}$ \\ ${ }^{1}$ Department of Saint-Petersburg State, Petersburg State Pediatric Medical University, Russia \\ ${ }^{2}$ Head of Department of Obstetrics and Gynecology with pediatric gynecology course Saint-Petersburg State Pediatric Medical University, Russia
}

Submission: June 19, 2020; Published: June 25, 2020

*Corresponding author: Semenova ER, Saint-Petersburg State Institution of Health Maternity hospital No. 1, Saint-Petersburg, Russia.

\begin{abstract}
The aim of our data is revealing the correlation between amniotic fluid index and fetal decompensation during labor in uncomplicated pregnancies at 40 weeks and beyond. 260 uncomplicated pregnant women at 40 weeks and beyond were examined by Ultrasound examination 48 hours before delivery. According to these dates all women were divided into 3 groups after amniotic fluid index. We analyzed fetus's condition during labor and just after delivery. In results we found out the following data: low amniotic fluid index does not associate with an increased risk of caesarean delivery for fetal distress. Did not confirm that low amniotic fluid index can use as perinatal morbidity prognosis. So for evaluation of fetus's condition we need another method, such as apparat cardiotocography and Doppler of fetus arteries.
\end{abstract}

Keywords: Amniotic fluid index; Fetal distress; Oligohydramnios

\section{Introduction}

An indirect estimate of the amount of amniotic fluid has long been included in all protocols of ultrasound findings as an indirect characteristic of the fetus. A decrease in the amount of amniotic fluid in periods of more than 40 weeks of pregnancy in the absence of an earlier detected pathology on the part of the fetus and mother is presumably a sign of worsening uteroplacental blood flow. This concept was proposed by some studies of dopplerometry of the renal arteries in fetuses with a reduced amount of amniotic fluid [1,2]. Other studies have not confirmed this fact, suggesting that the cause of oligohydramnios is rather a reduced fetal weight than redistribution of its blood flow [3]. Traditionally, oligohydramnios is associated with a high risk for the fetus in childbirth $[4,5]$. This may be the result of compression of the umbilical cord or potential placental insufficiency. There are many publications on the association of poor perinatal outcome and oligohydramnios [6-8]. Chauhan et al, [6] in a meta-analysis of 18 studies involving 10551 patients, demonstrated that antenatal and intrapartum values of the amniotic index less than $5 \mathrm{~cm}$ were associated with a significant risk of caesarean section or fetal distress and low Apgar scores at 5 minutes [6]. Unfortunately, this review, like many other similar publications relating to the association of oligohydramnios and perinatal outcomes, is not randomized and not coordinated according to the control groups of patients, inclusion groups, which can distort the overall picture. And only one of the above studies includes a randomized study of the amniotic index in women in labor [7]. It is logical to assume that these data can be extrapolated to similar situations in nulliparous women. Similarly, Casey et al. [8]. conducted a retrospective study of 6423 patients with a gestational age of more than 34 weeks and an amniotic index of $5 \mathrm{~cm}$. Low water was detected in $2.3 \%$ of cases and in most cases is associated with induction of labor, stillbirth, aspiration of meconium and neonatal mortality. There are studies with polar opposite results. Magann et al, [9] found that AI is a poor prognostic test for identifying pregnant women at risk for adverse perinatal outcomes. Rainford et al, [10] indicate a lack of correlation between AI indicators and the level of operational activity due to fetal distress, the number of newborns in need of mechanical ventilation of the newborn, and low Apgar scores. A study by Conway et al, [11] hypothesizes that isolated oligohydramnios during normal pregnancy is not associated with a decrease in the compensatory abilities of the fetus. The pathogenesis of oligohydramnios during pregnancy over 40 weeks, as well as the relationship of this indicator with the outcome of childbirth, is not well understood. What is the 
urgent need to study this issue in the light of the modern perinatal orientation of childbirth? The objective of our study is to identify the relationship between the value of the amniotic index and the risk of fetal distress in childbirth, which manifests itself in a decrease in the compensatory abilities of the fetus according to CTG, the outflow of amniotic fluid, densely stained with meconium. The pathogenesis of oligohydramnios during pregnancy over 40 weeks, as well as the relationship of this indicator with the outcome of childbirth, is not well understood. What is the urgent need to study this issue in the light of the modern perinatal orientation of childbirth? The objective of our study is to identify the relationship between the value of the amniotic index and the risk of fetal distress in childbirth, which manifests itself in a decrease in the compensatory abilities of the fetus according to CTG, the outflow of amniotic fluid, densely stained with meconium. The pathogenesis of oligohydramnios during pregnancy over 40 weeks, as well as the relationship of this indicator with the outcome of childbirth, is not well understood. What is the urgent need to study this issue in the light of the modern perinatal orientation of childbirth? The objective of our study is to identify the relationship between the value of the amniotic index and the risk of fetal distress in childbirth, which manifests itself in a decrease in the compensatory abilities of the fetus according to CTG, an outflow of amniotic fluid, densely stained with meconium.

\section{Materials and Methods}

In our retrospective study, we analyzed the amount of amniotic fluid using the amniotic index measurement method for the period from 2014 to 2018. and the relationship of this indicator with the percentage of cesarean section, performed due to fetal distress and estimates for SC. Apgar newborn at 1 and 5 minutes after birth. The study included 260 patients aged 18 to 41 years of gestation 40 weeks or more. Pregnant women with severe somatic pathology, as well as complications of pregnancy, who have indications for elective caesarean section, were excluded from the study. Patients with multiple pregnancies, with pelvic presentation and lateral position of the fetus were also excluded from the analysis. When assessing the outcome of childbirth, cases of operative delivery were taken into account only because of fetal distress detected either by cardiotocography (CTG) or by the flow of amniotic fluid densely stained with meconium. To analyze the studied indicators of pregnant women, the Statistica for Windows system was used.

\section{Results}

We had the following characteristics of the analyzed parameters in 260 women in labor (Table 1). The age of women ranged from 18 to 41 years and averaged $29.69 \pm 4.50$ years. The weight of the fetus after birth ranged from 2400 to $4880 \mathrm{~g}$., The average value of $3543.73 \pm 420.46$. Fetal growth averaged $52.42 \pm$ $1.97(47$ to $59 \mathrm{~cm}$ ). All newborns were assessed for their physical condition based on a clinical Apgar score at birth. At 1 minute, the score ranged from 1 to8 points (its average value was $7.70 \pm 0.73$ ), at 5 minutes from 0 to 9 points (an average of $8.69 \pm 0.76$ ). The amniotic index in the study group of patients ranged from 0 to $270 \mathrm{~mm}$ (average value $88.54 \pm 49.88$ ). Births occurred naturally in 145 women (55.8\%), cesarean section was performed in 115 women $(44.2 \%)$. There were no significant differences in AI in these groups (Figure 1). In pregnant women whose childbirth was completed by an emergency caesarean section, the scatter in AI values is somewhat wider. Correlation analysis did not reveal a relationship between AI values and the age of pregnant women, the duration and parity of labor, and also the characteristics of the newborn (weight, height, Apgar). For a more visual picture, we divided all pregnant women into 3 groups, based on the indicators of the amniotic index (AI) according to ultrasound data. Group 1 of pregnant women with AI more than $85 \mathrm{~mm}$, Group $2 \mathrm{AI}$ was in the range from 50 to $85 \mathrm{~mm}$, in Group 3, the index was determined below $50 \mathrm{~mm}$. (Figure 2) shows that the same AI levels during natural childbirth and Caesarean section are similar ( $\mathrm{P}>>0.05)$, as is the other, that the shares of delivery through Caesarean section are similar at different AI levels.

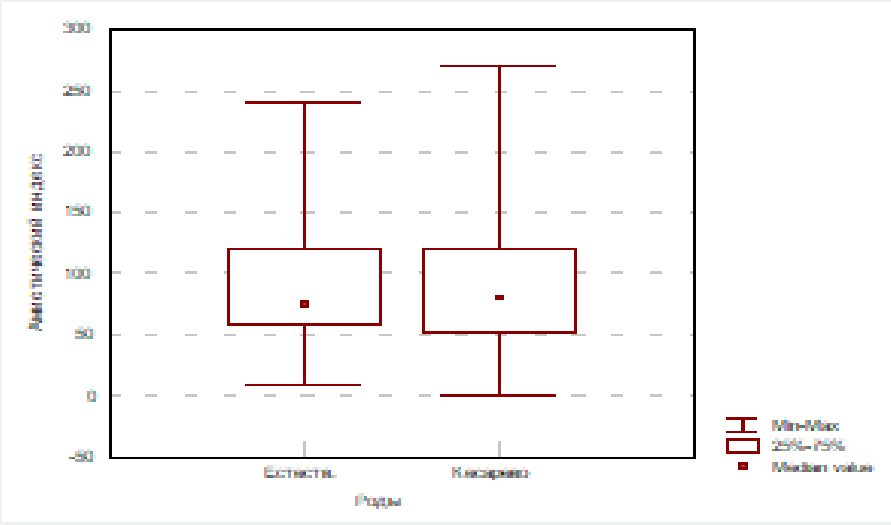

Figure 1: The characteristics of Al during natural childbirth and cesarean section. 


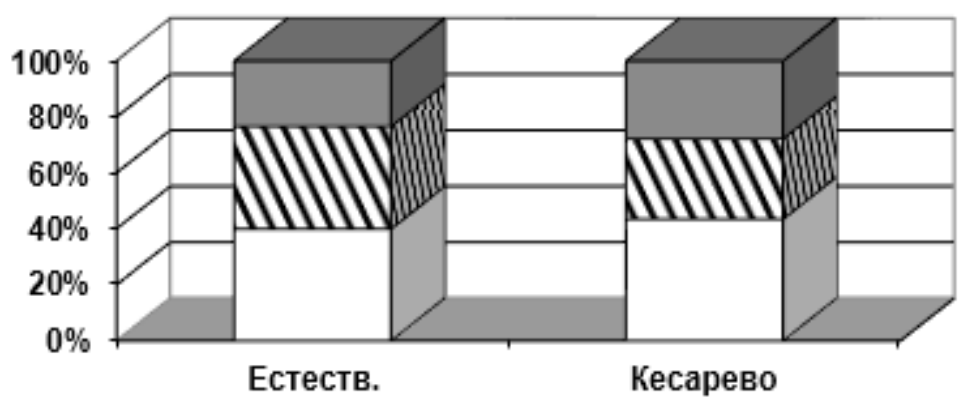

口АИ норма \50-85 чМенее 50

Figure 1: Birth outcomes in patients of various groups, divided by Al measured on the eve of childbirth.

\section{Discussion of the Results Findings}

As can be seen from the Table 1-2, neither in the group with the normal amount of amniotic fluid differences in the frequency of caesarean section ( $40 \%$ and $43.5 \%$ ), nor in the groups with a reduced amniotic index (36.55\% and $28.7 \%$ ), nor in the groups with severe oligohydramnios $(23.45 \%$ and $27.8 \%)$ showed no statistical differences. In the group with a normal amount of amniotic fluid, newborns born in a state of mild to moderate hypoxia were $20.37 \%$; in the 2 nd group $31.40 \%$ and in the 3 rd group of pregnant women $21.21 \%$. Significant differences in the characteristics of delivery at different AI levels were not detected (P >> 0.05). According to the results of our study, no causal relationship was found between a decrease in the amniotic index and a deterioration of the fetus during childbirth. Therefore, to assess the compensated condition of the fetus, additional diagnostic methods are needed.

Table 1: The indicators of the study group.

\begin{tabular}{|c|c|c|c|}
\hline Index & Mean & Minimum $\div$ Maximum & Me (LQ; UQ) \\
\hline Pregnant age & $29.69 \pm 4.50$ & $18 \div 41$ & $29(27 ; 33)$ \\
\hline Birth weight & $3543.73 \pm 420.46$ & $2400 \div 4880$ & $3500(3250 ; 3810)$ \\
\hline Fetal growth at birth & $52.42 \pm 1.97$ & $47 \div 59$ & $52(51 ; 54)$ \\
\hline SC score Apgar in 1 minute & $7.70 \pm 0.73$ & $1 \div 8$ & $8(8 ; 8)$ \\
\hline SC score Apgar in 1 minute & $8.69 \pm 0.76$ & $0 \div 9$ & $9(9 ; 9)$ \\
\hline Amniotic index & $88.54 \pm 49.88$ & $0 \div 270$ & $75.5(50 ; 120)$ \\
\hline
\end{tabular}

Table 2: Shows the summary data obtained as a result of the analysis of all childbirth histories of the studied group of patients.

\begin{tabular}{|c|c|c|c|c|c|c|c|c|}
\hline & 1 Group & & 2 Group & & & 3 Group & & Quantity \\
\hline & Bol 85 & & $50-85$ & & Men fifty & & Total & \\
\hline \multicolumn{9}{|c|}{ Childbirth } \\
\hline Natural. & 58 & $53.70 \%$ & 53 & $61.63 \%$ & 34 & $51.52 \%$ & 145 & $55.77 \%$ \\
\hline Cesarean section & fifty & $46.30 \%$ & 33 & $38.37 \%$ & 32 & $48.48 \%$ & 115 & $44.23 \%$ \\
\hline Total & 108 & $41.54 \%$ & 86 & $33.08 \%$ & 66 & $25.38 \%$ & 260 & $100.00 \%$ \\
\hline \multicolumn{9}{|c|}{ Apgar 1 min. } \\
\hline $\begin{array}{l}\text { Number of children with an } \\
\text { Apgar score of } 8 \text { or higher }\end{array}$ & 86 & $79.63 \%$ & 59 & $68.60 \%$ & 52 & $78.79 \%$ & 197 & $75.77 \%$ \\
\hline $\begin{array}{l}\text { Number of children with an } \\
\text { Apgar score of } 7 \text { or below }\end{array}$ & 22 & $20.37 \%$ & 27 & $31.40 \%$ & 14 & $21.21 \%$ & 63 & $24.23 \%$ \\
\hline Total & 108 & $41.54 \%$ & 86 & $33.08 \%$ & 66 & $25.38 \%$ & 260 & $100.00 \%$ \\
\hline
\end{tabular}




\section{References}

1. Veille JC, Penry M, Mueller Heubach E (1993) Fetal renal pulsed Doppler waveform in prolonged pregnancies. Am J Obstet Gynecol 169: 882-884.

2. Selam B, Koksal R, Ozcan T (2000) Fetal arterial and venous Doppler parameters in the interpretation of oligohydramnios in postterm pregnancies. Ultrasound Obstet Gynecol 15: 403-406.

3. Bar Hava I, Divon MY, Sardo M, Barnhard Y (1995) Is oligohydramnios in post term pregnancy associated with redistribution of fetal blood flow ? Am J Obstet Gynecol 173: 519-522.

4. Chamberlain PF, Manning FA, Morrison I, Harman CR, Lange I R (1984) Ultrasound evaluation of amniotic fluid volume. I. The relationship of marginal and decreased amniotic fluid volumes to perinatal outcome. Am J Obstet Gynecol 150: 245-249.

5. Manning FA, Hill LM, Platt L D (1981) Qualitative amniotic fluid volume determination by ultrasound: antepartum detection of intrauterine growth retardation. Am J Obstet Gynecol 139: 254-258.

6. Chauhan SP, Sanderson M, Hendrix NW, Magann EF, Devoe LD (1999)
Perinatal outcomes and amniotic fluid index in the antepartum and intrapartum periods: a meta-analysis .Am J Obstet Gynecol 181: 14731478.

7. Chauhan SP, Washburne JF, Magann EF, Perry KG, Martin JN, et al. (1995) A randomized study to assess the efficacy of the amniotic fluid index as a fetal admission test. Obstet Gynecol 86: 9-13.

8. Casey BM, Mc Intire DD, Bloom SL (2000) Pregnancy outcomes after antepartum diagnosis at or beyond 34 weeks gestation.Am J Obstet Gynecol 182: 909-912.

9. Magann EF, Chauhan SP, Kinsella MJ, McNamara MF, Whitworth NS, et al. (1999) Antenatal testing among 1001 patients at high risk: the role of ultrasonographic estimates of amniotic fluid volume. Am J Obstet Gynecol 180: 1330-1336.

10. Rainford M, Adair R, Scialli AR, Ghidini A, Spong CY (2001) Amniotic fluid index in the uncomplicated term pregnancy: prediction of outcome. J Reprod Med 46: 589-592.

11. Conway DL, Adkins WB, Schroeder B, Langer O (1998) Isolated oligohydramnios in the term pregnancy: is it a clinical entity? J Maternal Fetal Med 7: 197-200.

\section{Your next submission with Juniper Publishers will reach you the below assets}

- Quality Editorial service

- Swift Peer Review

- Reprints availability

- E-prints Service

- Manuscript Podcast for convenient understanding

- Global attainment for your research

- Manuscript accessibility in different formats

( Pdf, E-pub, Full Text, Audio)

- Unceasing customer service

Track the below URL for one-step submission https://juniperpublishers.com/online-submission.php 